\title{
CONSTRUÇÃO NACIONAL E APRENDIZADO POLÍTICO: o saber- poder da brasilidade
}

\author{
Fabrício Macielt
}

\begin{abstract}
Este artigo procura reunir elementos teóricos comparativos entre os processos de construção nacional europeu e brasileiro, de modo a analisar a especificidade do mito nacional desse último e sua relação com o aprendizado político no Brasil. Para tanto, as partes 1 e 2 do artigo procuram, a partir da obra de Michel Foucault Em defesa da sociedade (2005), analisar as narrativas mitológicas dos processos de construção nacional de Inglaterra e França, respectivamente. A parte 3 procura analisar, principalmente a partir da obra de Gilberto Freyre, a especificidade do processo de construção nacional e do mito da negação do conflito no Brasil. A parte final busca analisar uma possível afinidade eletiva entre o mito nacional e uma dificuldade de aprendizado político no Brasil.

PALAVRAS-CHAVE: construção nacional, mito nacional, conflito, aprendizado político, saber-poder.
\end{abstract}

Este artigo busca contribuir para uma aproximação analítica entre o processo de construção nacional, com ênfase no papel do mito nacional, e o potencial de aprendizado político no Brasil. ${ }^{1}$ Parte-se da compreensão de construção nacional como um processo histórico de mudança social em suas dimensões materiais e imateriais (Bendix, 1996). Procura-se compreender o aprendizado político como uma capacidade prática e reflexiva, incorporada e adquirida cognitivamente em experiências coletivas vividas por indivíduos de uma sociedade moderna (Dewey apud Honneth, 2000).

Com esse objetivo, busca-se apresentar uma comparação preliminar e parcial entre os casos de construção nacional da Inglaterra e da França e o caso brasileiro. Sobre os dois primeiros, a fonte

* Doutorando em Ciências Sociais pela Universidade Federal de Juiz de Fora. Realiza doutorado sanduíche em Freiburg-Alemanha. Pesquisador do Centro de pesquisa sobre desigualdade.

Universidade Federal de Juiz de Fora, Instituto de Ciências Humanas, Cidade Universitária, São Pedro, Juiz de Fora/ MG.macielfabricio@gmail.com

${ }^{1}$ Registro aqui meu agradecimento aos pareceristas anônimos da revista, cujas críticas e sugestões foram fundamentais para que eu conseguisse redigir esta versão final do texto. a que se recorre é o livro Em defesa da sociedade (2005) de Michel Foucault. Uma vasta literatura poderia ser mobilizada nesse ponto. No entanto, por motivos de espaço e pela eleição dos pontos analíticos que norteiam o artigo, os argumentos de Foucault nesse trabalho se apresentam como frutíferos. Como todo grande pensador do mundo moderno, ele possui um cerne de ideias e conceitos centrais que permeia vários livros. Como já é bem sabido, o conceito de "saber-poder" perpassa boa parte da obra geral de Michel Foucault. No citado livro não é diferente. $\mathrm{O}$ autor desenvolve, a partir da observação de casos concretos, a ideia de que todo saber social significa um exercício de poder nas lutas sociais. Cada grupo social possui um saber sobre si mesmo e sobre o mundo no qual vive, saber esse derivado de sua experiência no mundo e que expressa seus interesses. Assim, Foucault percebe os processos de construção nacional da Inglaterra e da França, tratados no livro. Eles são marcados pela luta entre o saber-poder de grupos distintos que disputam a hegemonia na nova forma de organização que se esboça no mundo moderno, ou seja, a nacional. 
O debate sobre nação, nacionalismos e identidades nacionais é um dos mais amplos nas ciências sociais contemporâneas, e não teríamos como retomá-lo aqui. Por isso, nos contentaremos em apresentar a contribuição de Michel Foucault na referida obra, uma vez que ela é pouco conhecida, por se tratar de um autor não conhecido como um teórico específico do tema da nação. Para ele, a nação moderna pode ser compreendida tanto em sua experiência prática quanto em sua narrativa, sendo essas duas dimensões inseparáveis do saber-poder (2005). Na primeira dimensão, podemos pensar a nação como um corpo político e como um agente coletivo. Esse agente não é homogêneo, mas composto por grupos e classes sociais distintos e em constante conflito. Na segunda dimensão, podemos pensar nas narrativas de tais grupos em disputa, bem como seus mitos, no interior da nação moderna, que buscam se estabelecer como uma narrativa central, ou seja, generalizar sua visão de mundo sobre as outras e se estabelecer como a narrativa dominante de todo o corpo político. Essa definição geral encontra diferenças importantes em cada caso histórico concreto. Isso porque os grupos sociais em conflito, que historicamente se transformam em classes dominantes e dominadas, nem sempre são os mesmos, bem como não o são os conteúdos simbólicos e ideológicos que precisam mobilizar para tanto.

Por isso, estudos comparativos, ainda que parciais e incompletos, são ferramentas importantes para a compreensão dos casos específicos. O valor da citada obra de Foucault se encontra nesse ponto, pois apresenta uma análise de cada um dos casos, investigando o encontro histórico, conflituoso e contingente entre os atores sociais e as narrativas especificas de cada caso, cujos resultados históricos quase nunca são previsíveis. Um efeito prático que parece ter decorrido do processo específico de construção nacional inglês e francês, ainda que ambos guardem diferenças significativas, é certo aprendizado político mediante a prescrição constante de metas políticas coletivas para a nação.

Tais metas significam a construção e a ma- nutenção de uma agenda política coletiva constante, de autossuperação e progresso, ou seja, de um telos social, fruto de narrativas em conflito que, para se mostrarem superiores a suas concorrentes, precisam atender a um critério universalista moderno (Taylor, 1997). Por isso, toda narrativa de um grupo que se pretende dominante não pode se mostrar como uma autonarrativa de grupo ou classe, mas precisa convencer de que seu conteúdo vislumbra o melhor modo de vida para toda a nação. Os casos concretos parecem sugerir que essa luta por convencimento quase nunca é simples, e, por isso, os mitos que sugerem a verdade sobre a história nacional se mostram socialmente eficazes.

Com isso em mente, veremos, na parte 1 do artigo, como a ideia de conquista faz parte da experiência prática e narrativa de grupos sociais que participam do processo de construção nacional inglês, bem como o papel que tal ideia exerce no potencial de aprendizado político daquela nação. Na parte 2, veremos como a construção de uma origem legítima, no caso francês, parece ter contribuído de forma bastante peculiar para o aprendizado político daquele povo.

Recorrendo a uma parte da literatura sobre a identidade nacional brasileira, e principalmente à obra de Gilberto Freyre, na parte 3 do artigo, buscaremos tematizar a especificidade histórica de nossa experiência de construção nacional. No caso brasileiro, a hipótese é a de que a forte presença de um mito negador do conflito e a ausência de mitos concorrentes com o da brasilidade pode ter alguma afinidade eletiva com um fraco potencial de aprendizado político, necessário para uma autopercepção como comunidade política e para o engajamento em assuntos coletivos.

\section{A EXPERIÊNCIA MITOLÓGICO-NARRATIVA DA INGLATERRA}

Antes de entrar na recontagem da história mitológico-narrativa da Inglaterra e da França efetuada por Foucault, é preciso compreen- 
der diante de que tal narrativa foi necessária. Trata-se do discurso histórico predominante a partir de Hobbes, em que a ideia montada em torno do Leviatã procurou velar, segundo Foucault, toda uma perspectiva de conquistas na constituição corporal e ideal daquelas nações, fazendo parecer que a história define-se simplesmente como a guerra de todos contra todos. Por isso, Foucault diz que todo esse ideal hobbesiano atuou no sentido de eliminar do discurso histórico e da prática política a utilização da ideia de conquista, fazendo parecer natural todo o corpo social até então. "O adversário invisível do Leviatã é a conquista” (Foucault, 2005, p.113).

É diante de tal perspectiva que Foucault procura reconstruir a história mitológica da Inglaterra e da França, ressaltando a legitimidade de suas conquistas em contradição com uma suposta soberania natural do Leviatã. Aqui é interessante observar como o conteúdo cognitivo derivado de narrativas populares se apresentou como um combustível histórico fundamental tanto para a coesão do corpo nacional, mediante a prescrição constante de uma agenda política e de metas coletivas bem específicas, quanto para o aprendizado político de tais nações, uma vez que o desenvolvimento, como que de baixo pra cima, do ideal e da prática de instituições centrais das nações modernas depende diretamente do engajamento prático nessa espécie de telos nacional que então se formou.

Pois bem, entremos na história inglesa com Foucault. Parece que é na Inglaterra que, pela primeira vez, surge o discurso de uma guerra civil permanente, contrariando o contrato hobbesiano protetor do Estado moderno. Dois elementos históricos podem justificar isso. Primeiro, Foucault remete-se à precocidade da luta política da burguesia inglesa contra a monarquia absoluta e a aristocracia. Segundo, a consciência, já viva há séculos, mesmo nas camadas pobres, do fato histórico da velha clivagem da conquista (Foucault, 2005, p.115).

A presença da ideia de conquista na Inglaterra remonta à conquista normanda de Guilher- me e manifestou-se de muitas formas nas instituições e na experiência histórica dos súditos políticos ingleses. Também no direito, sua força é intensa, pois, devido ao fato de os ingleses terem possuído por muito tempo um direito formulado de cima e em idioma estrangeiro, ele era a presença de um estigma estrangeiro, a marca de outra nação. Por isso, uma espécie de "sofrimento linguístico" desse povo (2005, p.115), por não poder se defender juridicamente em seu próprio idioma, diante de uma figura estrangeira da lei, fez levantar, para Foucault, na Idade Média, uma voz contestadora que reivindicava um direito próprio, na própria língua, unificado por baixo, a partir de uma lei comum opositora de estatutos régios. Tal mudança dependeria de uma recontagem da história do saber-poder inglês.

Aqui, o conflito narrativo-mitológico que se esboça gira em torno do embate entre um conjunto de narrativas saxãs populares, como crenças míticas, cultos a reis santos e narrativas populares, como a do Robin Hood, e, por outro lado, um conjunto de lendas aristocráticas e quase monárquicas, que se desenvolveram na corte dos reis normandos e foram reativadas no século XVI, durante o desenvolvimento do absolutismo monárquico dos Tudor, ou seja, trata-se essencialmente da lenda do ciclo arturiano. Essa lenda não-saxã é a reativação de velhas lendas célticas redescobertas pelos normandos sob a camada saxã das populações. Isso só foi possível, em proveito da monarquia normanda, devido às relações que havia entre os normandos e os bretões. Assim, temos dois conjuntos mitológicos bem fortes, em torno dos quais a Inglaterra sonhava, de formas bem diferentes, seu passado e sua história (Foucault, 2005, p.117).

Só o fato de haver, no caso inglês, um conflito entre narrativas, disputando a verdade e, consequentemente, o lugar onde o poder nacional habitaria a partir da verdade vencedora, antes mesmo de sabermos quem venceu, já é um dado importante para a análise deste artigo. Isso porque tal disputa mobilizadora de interesses divergentes coloca toda a nação em ebulição 
diante de sua própria história, exigindo uma guerra de saber-poder, na qual grande parte da população está cotidianamente envolvida, o que apresenta uma possibilidade importante de engajamento e, por isso, de aprendizado político para a maioria dos cidadãos. Tal história nacional se monta exigindo de seus súditos, em grande medida, um posicionamento diante de mitos distintos em conflito, o que obriga as pessoas, em boa medida, a refletirem sobre seu passado, presente e futuro. No caso brasileiro, como veremos, parece que nosso mito nunca teve nenhuma outra narrativa concorrente, pelo menos que se solidificasse suficientemente para tanto, que contestasse sua veracidade mitológico-histórica.

Por exemplo, Foucault mostra que tal cenário narrativo inglês possibilitou o surgimento de uma memória histórica de revoltas, com efeitos políticos bem precisos. Primeiro, estava articulado certo direito do povo inglês de expulsar estrangeiros. Havia uma série de elementos que permitiam codificar as grandes oposições sociais nas formas históricas da conquista e da dominação, inclusive de uma raça sobre outra, dentro do cenário nacional inglês. Com isso, é possível ver que os conflitos, políticos, econômicos ou jurídicos, eram, devido a esses elementos, com pouca dificuldade articulados, codificados e transformados em discurso, principalmente em discursos de oposição de raças. Assim, essa codificação de um conflito entre raças, essa clivagem de raças em sistemas de oposição, apresentou-se como uma espécie de instrumento, ao mesmo tempo discursivo e político, que permitia a ambos os lados formularem suas próprias teses. O importante a se notar aqui é o ambiente de ebulição política permanente que se instaura na vida cotidiana da nação, diante de tais oposições.

Foucault complementa dizendo que a discussão jurídico-política dos direitos do soberano e dos direitos do povo ocorreu na Inglaterra, no século XVII, a partir dessa espécie de vocabulário engendrado pelo fato da conquista, pela relação de dominação de uma raça sobre a outra e pela revolta, ou pelo menos pela ameaça cons- tante de revolta, dos vencidos contra os vencedores (2005, p.118).

Foi assim que, por exemplo, o "discurso do rei” se consolidou, principalmente com Jaime I, declarando que o rei senta-se no trono de Deus, remetendo-se evidentemente à teoria teológicopolítica do direito divino. Todavia essa eleição divina, permitindo uma propriedade efetiva da Inglaterra, tinha um sinal e um ancoramento histórico na vitória normanda. Por isso, o direito não deveria ser, nessa perspectiva, um direito comum às diferentes populações sobre as quais se exerça a soberania, mas sim um direito que é a própria marca da soberania normanda, estabelecido por eles e evidentemente para eles. Aqui, uma estranha analogia fortalecia tal discurso, bem resumida, segundo Foucault, nas palavras de Blackwood, em 1581, traçando um paralelo entre Guilherme, o Conquistador, e Carlos V em sua atuação na América. Ele dizia que a situação da Inglaterra, na época da invasão normanda, devia ser compreendida como era compreendida naquele momento a situação da América diante das potências que ainda não se denominavam coloniais. Isso ressalta bem um certo "colonialismo interno" europeu (Foucault, 2005, p.121) refletido nos vários mecanismos de poder do Ocidente, desdobrado em seus aparelhos, instituições e técnicas de poder.

A resposta do parlamento ao rei, nessa oposição binária das raças inglesas, é bem interessante. Ela procura recontar a história de Guilherme, de modo a desmascarar sua legitimidade e mostrar as vísceras dominadoras de seu poder. Uma interessante ilustração sobre isso, lembrada por Foucault, surge em um texto chamado Argumentun Anti-Normannicum, onde uma espécie de vinheta dispunha, em uma faixa, uma batalha, duas tropas armadas, tratandose, evidentemente, dos normandos e dos saxões na batalha de Hastings, e, no meio, o cadáver do rei Haroldo, sugerindo que ali a monarquia legítima desapareceu de fato. Embaixo, havia uma cena, em formato maior, representando Guilherme coroado, onde uma estátua de nome Britânia estende a ele um papel com os dizeres: "Leis da 
Inglaterra”. Ele recebe a coroa de um arcebispo de York, enquanto outro eclesiástico entrega-lhe um papel dizendo: "Juramento do rei". Com isso, afirma-se que Guilherme não é o herdeiro legítimo, cuja soberania está limitada pelas leis da Inglaterra, pelo reconhecimento da igreja e pelo juramento prestado. Como disse o Churchill do século XVII, Guilherme assim não conquistou a Inglaterra, mas foram os ingleses que conquistaram Guilherme. Foi depois dessa transferência perfeitamente legítima do poder saxão para o rei normando, segundo os parlamentaristas, que começou realmente a conquista, ou seja, todo um jogo de espoliações, desmandos e abuso de direito. É nisso que consiste o "normandismo", como uma deturpação, um jugo dissimétrico, um regime político sistematicamente favorável à aristocracia e à monarquia normandas. Foi contra isso que ocorreram todas as revoltas da Idade Média, que foram impostos direitos do Parlamento como verdadeiro herdeiro da tradição saxã. Também foi contra tal "normandismo" que lutaram os tribunais inferiores quando buscaram impor uma "lei comum" contra os estatutos régios.

Todo esse cenário histórico inglês ilustra muito bem como ocorreu uma disputa constante, onde o poder, por vezes, mudou de mãos entre vários segmentos sociais, ou mesmo entre nações, compreendidas por Foucault como grupos identificados por interesses históricos comuns muito mais do que por uma suposta origem comum. Tal disputa constante manteve um imaginário de conflito permanente, o que é fundamental para a constituição de uma nação onde seus súditos são envolvidos politicamente em seus projetos de conquista. Esse cenário de lutas permanentes é o que estipula o estabelecimento de metas coletivas de longo prazo, obrigando um engajamento, mesmo que não seja de toda a população, mas de bom número dos cidadãos, em tal projeto comum, ressaltando, assim, como funciona a dimensão fáctica das modernas "comunidades imaginadas" de Anderson (1991) e como tal fato se impõe objetivamente como possibilidade de aprendizado político e desenvolvi- mento de recursos cognitivos para o engajamento em assuntos coletivos.

Tudo isso, na verdade, significou uma construção mitológica de um direito saxão perfeito. A perspectiva dos parlamentares, naquele momento, intencionados a montar uma república nova com base naquele direito, ressaltava se tratar de um direito bem próximo à razão humana, pois na ordem civil seria quase igual ao de Atenas, na militar quase igual ao de Esparta, e quanto ao conteúdo das leis religiosas e morais, semelhante às leis de Moisés. Com isso, o saxão seria um Estado Perfeito (Foucault, 2005, p.126). Assim, o historicismo que se opõe aqui ao absolutismo, conforme Foucault, apontava para uma utopia fundadora, onde se fundiam uma teoria dos direitos naturais, um modelo histórico valorizado e o sonho de uma espécie de reino de Deus. O importante aqui é notar que o poder estaria ao lado de quem tivesse a melhor legitimidade histórica, e que só o fato de haver um embate constante pela posse de tal legitimidade já põe a nação em um estado de questionamento permanente de seu imaginário, que, na verdade, é montado o tempo inteiro sobre essa espécie de guerra moral e ideológica constante.

Outro ponto importante ressaltado por Foucault é que a crítica mais radical ao monarquismo inglês foi proveniente de camadas mais populares e, principalmente, do discurso pequeno-burguês. Para esses, toda a prevalência da monarquia não passou de um domínio de roubo e rapina, num cenário onde Guilherme teria transformado seus antigos companheiros de banditismo e pilhagem em duques, barões e lordes. Com isso, o regime de propriedade se tornava totalmente invalidado, pois sua origem derivava do fato da conquista. Assim, a revolta popular assume o caráter da face oposta da guerra, uma vez que a face permanente é a lei, o poder e o governo. No geral, a postura pequeno-burguesa, bem como seu discurso, parece ter buscado denunciar a grande guerra velada pelo discurso oficial soberano, ou seja, aquela praticada pelo próprio Estado velador dos segmentos sociais que, por trás dele, leva- 
vam todas as vantagens. A ideia era mostrar que as revoltas populares não estavam iniciando uma guerra, mas sim respondendo defensivamente a esse estado de guerra permanente no qual as camadas populares eram as mais prejudicadas. É exatamente esse imaginário de guerra latente que oferece a oportunidade social de mobilização, engajamento e aprendizado político, que parece fraco no caso brasileiro, uma vez que qualquer ideia de conflito sempre foi algo rigorosamente negado por nosso mito.

O que Foucault está tentando analisar com toda essa dinâmica em torno do poder é que, uma vez que o próprio regime saxão evocado poderia ser apenas mais um regime de dominação reprodutor da mesma lógica, no fundo, a dominação começa com qualquer forma de poder, ou seja, que não há formas históricas de poder que possam ser analisadas a não ser em termos da dominação de uns sobre os outros. Está formulada aqui a ideia de que toda lei, toda forma de soberania e todo tipo de poder devem ser entendidos não nos termos do direito natural e da constituição da soberania, mas como o movimento indefinido das relações de dominação (2005, p.131).

Por fim, Foucault quer evidenciar, com tudo isso, a permanência de um esquema binário, concretizado em uma luta constante de raças, na trajetória de montagem dos mitos nacionais e de sua legitimidade. Com esse movimento de ascensão das revoltas, que tomaram o imaginário da Idade Média, vemos, pela primeira vez, esse esquema binário articular-se a partir dos fatos de nacionalidade, tais como a língua, país de origem, hábitos ancestrais, espessura de um passado comum, existência de um direito arcaico e a redescoberta de novas leis (2005, p.131). Ele permitia, assim, decifrar, em toda a sua extensão histórica, todo um conjunto de instituições com a sua evolução, o que me parece ter sido fundamental para a tematização da verdadeira questão social em jogo, ou seja, uma luta de raças velada e, consequentemente, fértil para o desenvolvimento de um potencial de aprendi- zado político. A identificação daquele esquema permitiu ainda analisar as instituições atuais em termos de enfrentamento e de guerra, a um só tempo cientificamente, hipocritamente e violentamente travada entre as raças (p.131).

A interessante contribuição que Foucault apresenta aqui é a identificação de uma trama histórica que possibilitou a politização de segmentos sociais europeus em uma medida significativa o suficiente para a posterior generalização de um padrão de igualdade formal e prática, para todas as classes, com a consolidação da burguesia, quando ela finalmente conquista o Estado, e, consequentemente, a generalização da cidadania. O "historicismo político" (2005, p.132) identificado aqui, como disputa permanente pela legitimidade de uma origem pautada sempre em argumentos míticos, além de mostrar toda a dinâmica de construção das tradições e de estabelecimento das relações de poder, permitiu o desmonte ideológico da soberania filosófico-jurídica do Leviatã de Hobbes, que sacralizava um Estado soberano omitindo todo o sangue derramado necessário para sua imposição, como se ele tivesse naturalmente se estabelecido e sobrevivido, e como se sobrevivesse normalmente, como se nada conflituoso estivesse acontecendo no cotidiano de seus súditos. ${ }^{2}$

\section{AEXPERIÊNCIA MITOLÓGICO-NARRATIVA DAFRANÇA}

A construção do saber mitológico nacional da França é outro caso emblemático para os objetivos deste artigo. Para Foucault, a construção do mito francês - de descendência direta dos troianos -, numa espécie de ramo paralelo à descendência romana, foi fundamental para o

Uma extensa literatura acerca de Hobbes poderia ser mobilizada aqui, tanto para defendê-lo quanto para criticá-lo. No entanto, por motivos de espaço e objetivos deste artigo, trata-se aqui apenas da visão de Foucault acerca de algumas dificuldades da teoria do Leviatã. O ponto mais importante, entretanto, é sua percepção acerca das lutas importante, entretanto, é sua percepção acerca das lutas específico de construção nacional. 
estabelecimento do direito francês. Para ele, trata-se de um discurso que teve uma função bem precisa, menos de narrar o passado e contar as origens, quanto a de formular um direito de poder específico. Foi uma verdadeira lição de direito público. Assim tal narrativa circulou.

O telos político elaborado por tal projeto é nítido, por exemplo, no fato de que, se os francos são irmãos dos romanos, em sua condição semelhante à de fugitivos de Troia, eles teriam naturalmente o direito de herança diante da queda do Estado Romano. Foi assim que a soberania do Rei da França, naquele momento, se expandiu sobre os ex-súditos do Império Romano. $\mathrm{O}$ direito do rei era o direito romano. Assim, a lenda de Troia foi uma maneira de narrar com imagens o princípio histórico-mítico formulado na Idade Média acerca do poder monárquico e ancorado nos direitos imperiais codificados na época de Justiniano.

Toda essa construção mitológica atribuía, assim, à França direitos históricos iguais aos de Roma. Isso permitia uma liberdade histórica para o exercício do poder, pois deixava claro que a França não dependia de nenhuma monarquia universal que porventura tentasse ressuscitar o Império Romano. A França tornara-se, com isso, tão imperial quanto qualquer outro descendente do Império Romano, como o Império Alemão, por exemplo. Ficava isenta de qualquer laço de vassalismo diante de seus adversários históricos.

Desse modo, houve um vínculo, desde o século XVI, entre a delimitação do direito da monarquia, a reconstituição de um modelo passado, e a revolução como exumação de uma constituição fundamental e esquecida. Por um tempo, houve também a necessidade francesa de contornar um discurso que sustentava uma possível origem germânica. Para contornar tal ideia, Foucault ressalta que, dentre diversos recursos de saber-poder, foram praticados especialmente dois. Primeiro, uma espécie de volta ao mito troiano, que se reativou em meados do século XVII. Depois, a fundação e introdução de um tema completamente novo e que passa a ser fundamental para a narrativa mitológica francesa: o "galo-centrismo" radical (Foucault, 2005, p.145). A partir do século XVII, os gauleses se transformam no motor principal dessa história. Numa verdadeira inversão das polaridades e dos valores, agora são os germanos que aparecem como mera continuidade, como mero episódio na história dos gauleses. Aqui, a nação francesa surge como a grande matriz de todos os povos da Europa. Assim, os francos que, nos séculos IV e V, invadiram a Gália, não passavam de descendentes dessa espécie de "Gália primitiva" (2005, p.146), pois eram simplesmente gauleses ávidos de rever seu país. Não era um absurdo para eles libertar seus irmãos vencidos de uma Gália escravizada. Numa jogada histórica de saber-poder fundamental, não destruíram o direito romano vigente, mas deixaram-se absorver por ele. ${ }^{3}$

Para Foucault, toda essa fábula permitia afirmar o caráter autóctone dos gauleses, bem como a existência de fronteiras naturais da Gália. Tratava-se ainda de apagar qualquer diferença racial e qualquer heterogeneidade entre um direito germânico, concorrente, e um direito romano. Por isso, era necessário mostrar que os germanos haviam renunciado ao seu próprio direito para adotar o sistema jurídico-político dos romanos. Também foi fundamental fazer os feudos e as prerrogativas da nobreza derivarem não dos direitos fundamentais e arcaicos dessa mesma nobreza, mas simplesmente de uma vontade do rei, cujo poder e absolutismo seriam anteriores à própria organização do feudalismo. No geral, trata-se da construção de um saber mitológico geopolítico, para a conquista de poder e hegemonia, ou seja: transferir a pretensão da monarquia universal para o lado francês. Foi assim que a Gália se transformou, nas palavras de Tácito, a vagina nationum (Foucault, 2005, p.147).

${ }^{3}$ Cabe ressaltar que, assim como no caso inglês, os atores sociais envolvidos nesses conflitos geralmente pertencem a classes dominantes, como a burguesia ou a aristocracia. No entanto, Foucault sugere, ao longo de sua obra, que muitas das formulações ideológicas de tais atores são sistematizacões de ideias e sentimentos surgidos no cotidiano de camadas sociais populares, cujas adesões às narrativas dominantes são parte importante para o tipo de dominação moderna que já se esboça em tais casos nacionais. 
O ponto em comum de tudo isso, identificado por Foucault com a narrativa inglesa, é o fato de que a invasão, com todo seu formato, causas e consequências, tornou-se um problema histórico, considerando estar em jogo o importante fato jurídico-político de que compete à invasão dizer o que são a natureza, os direitos e os limites do poder monárquico. Ele resume com a assertiva de que é à invasão que se pede a formulação dos próprios princípios do direito público.

No geral, é preciso compreender que se trata aqui de uma construção de um novo campo histórico, onde uma diferença importante em relação à Inglaterra se faz presente. Nela, a conquista e a dualidade racial de normandos e saxões constituíram o ponto essencial de articulação da história. Na França, por outro lado, até finais do século XVII, segundo Foucault, simplesmente não houve heterogeneidade alguma no corpo da nação, e todo o fabuloso sistema de parentesco entre gauleses e troianos, bem como posteriormente entre os primeiros e os germanos, depois entre gauleses e romanos, permitiu assegurar uma continuidade na transmissão do poder e uma homogeneidade sem muitos problemas no corpo da nação (Foucault, 2005, p.150).

A ênfase de Foucault é sobre um discurso acerca de uma narrativa que procurou, no caso francês, esconder uma dualidade nacional latente, oriunda de uma luta entre vários segmentos sociais no interior da nação, em uma espécie de transição entre uma luta de raças para a moderna luta de classes, que disputava o poder de construção do saber oficial, o que dialeticamente conferiria um poder de classe para o segmento vencedor. Isso é o que ele tratou como um problema de "pedagogia política", que consistia em saber de onde viria o saber-poder constituidor do direito e da hegemonia nacional (2005, p.151).

Tanto na produção intelectual dos principais historiadores franceses da época quanto à atuação do Estado, como no episódio em que Luís XIV encomenda relatórios acerca da administração do país - e que resulta no trabalho de Boulainvilliers, valorizando teses que favoreci- am a nobreza -, é nítida a montagem desse discurso denunciado por Foucault que, coerente com sua tese geral de que saber é poder, está com isso fazendo o mesmo, ou seja, recontando a história. Dessa vez, porém, ela vem "em defesa da sociedade", ou seja, contra a história oficial do saber jurídico-filosófico inspirado no Leviatã e que se revezou no favorecimento da nobreza e da aristocracia até então. Assim, tratou-se de contestar um saber concedido ao rei, que era fabricado pela própria máquina administrativa, ou seja, o saber do rei acerca dos súditos era completamente colonizado e prescrito pelo saber do Estado acerca do Estado. Com isso, a administração pública permitia ao rei governar sobre o país com uma vontade sem limites.

Desse modo, a recontagem da história dependia de uma espécie de "contra-saber" (Foucault, 2005, p.156) que abalasse o saber comum aos reis e aos nobres, ou seja, aquela lei implícita, aquele compromisso recíproco do rei com sua aristocracia. O grande inimigo desse novo saber era, de fato, o saber jurídico constituído historicamente até então. Foi contra tal saber de escrivães que se tornou necessário valorizar outra forma de saber que se concretizou no próprio formato da história contemporânea. Esse formato, ancorado por uma nobreza traída do início do século XVIII, buscava valorizar outra forma de conhecimento, em torno de uma história das riquezas, e não mais econômica, uma história dos deslocamentos das riquezas, ou seja, das extorsões, dos roubos, dos desvios, enfim, um novo saber que denunciasse todo o sangue derramado e toda a guerra entre espécies implícita na perfeição do Leviatã francês, sustentada pelo saber-poder oficial de sua soberania guerreira. É essa dinâmica de guerra entre saberes que, para Foucault, faz explodir o próprio funcionamento do saber histórico (2005, p.159).

Aquele momento histórico presenciou, na verdade, a construção de um novo sujeito histórico do saber-poder: a nação, como elemento mitológico que sorrateiramente perpassa o tempo sob o Estado e seu direito oficial, ao mesmo 
tempo mais antiga e profunda do que qualquer instituição. Ela é, ao mesmo tempo, quem fala e de quem se fala na narrativa histórica, confundindo-se com a própria ideia genérica de sociedade como conjunto de indivíduos reunidos por um estatuto, por costumes e por uma lei particular, que se define muito mais pela prática do que pelo saber oficial.

Assim, a nação não era definida por nenhuma unidade territorial, por nenhuma morfologia política ou pela sujeição a um império qualquer. Tais conjuntos de pessoas comuns eram muito mais precisados pela posse histórica - e é aqui que entram os discursos acerca das origens mitológicas comuns, conferindo identidade e coesão social - de uma espécie de regularidade histórica. A nação circulava por trás das fronteiras e das instituições formais. Esse é um conceito de nação, segundo Foucault, que nos remete para além das afinidades étnicas e linguísticas, pois o que está em jogo aqui é a posse de um estatuto histórico comum, ou seja, a posse de uma origem comum mitologicamente construída e, a partir dela, de todo um telos comum a ser perseguido, ou seja, de todo um conjunto de interesses que escapam às fronteiras de origens naturais comuns e que dependem inteiramente da reconstrução constante de novos saberes para o seu alcance.

Tal dinâmica de recontagem da história em torno da nação consistiu, segundo Foucault, na desativação ritual dos atos fundamentais do antigo poder, em uma decifração sistemática de suas intenções e na rememoração de tudo que ele se esforçou para "esquecer". Em suma, foi um método de denúncia daquilo que teria sido o grande "mal da história". No geral, tratou-se de um novo pathos, um novo discurso, uma paixão quase que erótica pelo saber histórico, uma perversão sistemática de uma inteligência interpretativa, bem como de uma obstinação de denúncia, uma articulação da história baseada em um verdadeiro e sorrateiro golpe no Estado (Foucault, 2005, p.162). É interessante notar que tal discurso, uma vez provadas sua força e seu poder, passou a ser disputado por vários grupos dominantes, em torno dos Estados, e é claro que a própria monarquia, ao mesmo tempo reconhecendo a eficácia do novo tipo de poder em voga e instrumentalizando sua relação com ele, também entrou nessa guerra em torno do saber-poder consolidado pela ideia de nação.

Talvez a principal diferença entre os casos de Inglaterra e França seja que a primeira é fundamentalmente marcada pela presença da narrativa da conquista. Aqui vale ressaltar que um mito, para além de mera ideologia que pode e deve ser criticada, também possui função prática, influencia a vida das pessoas. Uma nação que se percebe como guerreira e descendente de guerreiros parece apresentar boas disposições para o conflito e a prática democrática. A França, por outro lado, ainda que tenha conseguido alcançar uma certa homogeneidade em seu mito nacional por longo tempo, precisou desenvolve-lo por meio de uma guerra externa aos limites da nação, sendo ela principalmente contra os germanos, pois isso era o que o contexto europeu da época parecia exigir para o estabelecimento do poder nacional. ${ }^{4}$ Assim, a França só pôde estabelecer sua homogeneidade mediante fortes conflitos de saber-poder no contexto europeu, para provar que era uma nação mais legítima, inclusive por meio do seu direito, do que seus vizinhos. Tal disputa externa parece ter contribuído significativamente para o aprendizado político daquela nação.

\section{AEXPERIÊNCIA MITOLÓGICO-NARRATIVA DOBRASIL}

Outros casos de construção nacional europeus, que não teríamos espaço para desenvolver aqui, poderiam ser frutíferos numa comparação com o caso brasileiro. Por exemplo, os casos nórdicos da Dinamarca (Ostergard, 2004) e da Suécia (Wittrock, 2004) também permitiri-

4 Vale a pena conferir a obra de Louis Dumont "German Ideology” (1994), para uma melhor compreensão da relação entre a identidade nacional francesa e a alemã. 
am esboçar a ideia comparativa que relaciona a construção dos mitos e, consequentemente, das identidades nacionais com a prescrição histórica de uma agenda política coletiva, entendendo-se esse processo como fundamental para a construção de um telos para o futuro e, em decorrência disso, para a construção prática da democracia.

No caso brasileiro, Gilberto Freyre continua sendo uma das principais referências para a construção do mito e para o estudo do processo de construção nacional. Esse nosso clássico desenvolveu tanto uma análise sobre a nossa formação concreta quanto contribuiu para a sistematização de nosso mito. Quanto ao primeiro ponto, Freyre desenvolve, em seu livro Sobrados e Mucambos, aquela que parece ser a primeira tentativa sistemática de explicar a sociedade brasileira formalmente independente. Sua contribuição explicita como o modo de vida moderno paulatinamente precisa substituir o potentado patriarcal no Brasil (Souza, 2000). Essa é uma parte importante na compreensão de nosso processo de construção nacional, pois tal processo precisa considerar os efeitos que instituições como Estado e mercado exercem na vida prática de todas as classes sociais da nação. Outro livro clássico, que complementa o entendimento de nossa construção nacional, é $A$ revolução burguesa no Brasil de Florestan Fernandes. Segundo Jessé Souza (2000), a análise macroestrutural de Florestan complementa a de Freyre, culturalista, e atenta aos aspectos da mudança na vida cotidiana. Isso porque Florestan percebe como a fundação do Estado moderno brasileiro, com a independência, rearticula a relação entre as classes sociais, por meio das estruturas econômicas do capitalismo moderno.

Além da dimensão prática de mudança social que uma sociedade moderna vivencia em sua dinâmica de construção nacional, é preciso também levar em conta a dimensão imaterial do processo, ou seja, a dimensão da identidade nacional e de seu mito constitutivo. Nessa dimensão, Gilberto Freyre também e um autor essencial. Foi no primeiro livro de sua trilogia, o Casa Grande \& Senzala, que ele desenvolveu os crité- rios que se tornaram dominantes para definir a identidade brasileira. Eles são conhecidos e o mote de amplo debate. Trata-se de uma suposta capacidade brasileira de miscibilidade, amálgama de opostos, hospitalidade, pacificidade e sensualidade, derivadas de um sadomasoquismo social, possível apenas em uma formação na qual a proximidade física era um traço constitutivo.

Entretanto, o livro remete a uma realidade que começa a desaparecer já no século XVIII. Longa bibliografia ajuda a analisar como aqueles traços constitutivos iniciais viram ideologia. Dentre ela, destacam-se trabalhos clássicos, como os de Dante Moreira Leite e Carlos Guilherme Motta, e trabalhos mais recentes como os de Ricardo Benzaquen e Jessé Souza. Todos contribuem para o entendimento de como o mito da brasilidade se constrói e eterniza no tempo, como ele se opera como saber-poder, a partir das ideias iniciais de Freyre. Ao longo de mais de quarenta reedições, Casa Grande continua sendo a referência para nossa autocompreensão, reproduzida explicitamente ou não na academia e no senso comum. Tais ideias chegam até essa dimensão da vida cotidiana principalmente por meio do mecanismo formal da escola, desde Getúlio Vargas, quando passam a ser doutrina oficial da educação básica (Souza, 2003).

O saber-poder da brasilidade só se torna realidade em sua influência na construção nacional por meio de instituições concretas. Além da escola, o saber-poder de nosso mito toma forma em nossa historiografia oficial, como na influente ideia de "homem cordial", guia-central de outro de nossos mais influentes livros, o Raízes do Brasil de Sérgio B. de Holanda. O saber-poder tem influência prática na construção nacional porque passa a ser aprendido não apenas na escola, mas reproduzido na imprensa da época e como discurso do Estado Novo, ainda que Freyre e Vargas, como indivíduos, não tivessem necessariamente alguma ligação ou afinidade (Souza, 2003). Ou seja, todas as instituições nacionais brasileiras precisavam de uma justificativa ideológica e moral para legitimar a dimensão sem 
precedentes que o contexto dos anos 30 presenciava na construção nacional brasileira, no qual nossa urbanização e industrialização tomam dimensões sem precedentes (2003).

É assim que o saber-poder da brasilidade, com seu conteúdo específico sugerindo nossa capacidade de amálgama de opostos, contribui incisivamente com a coesão e a integração social operada pelo Estado Novo. Não entraremos na crítica ao Estado Novo, mas precisamos compreender como ele exigiu um saber-poder específico para sua realização, o qual tinha legitimidade exatamente por derivar da historiografia oficial de pensadores como Freyre e Sérgio Buarque. Seu ensaísmo, ao mesmo tempo, explicava o Brasil, montava um mito e, assim, atuava como saberpoder prático na construção da sociedade brasileira sob os moldes de um Estado nacional com dimensões institucionais inéditas. Uma dessas atuações institucionais é a conhecida formação do SPHAN $^{5}$ para mapear o arquivo cultural brasileiro, no qual Buarque e Freyre foram intelectuais atuantes (Rubino, 1996).

Compreendemos ainda melhor a eficácia de obras como as de Freyre e Buarque quando mapeamos seu contexto de ideias nos anos $30 .^{6}$ Nenhum contexto de mudanças políticas profundas existe sem a consolidação de um conjunto de interpretações sobre ele que discordam em alguns aspectos e concordam em outros. Aparentemente contrários à perspectiva de suavização do "caráter" nacional brasileiro, como em Freyre e Buarque, o contexto dos anos 30 apresenta a obra considerada autoritária de Oliveira Vianna e Alberto Torres, só para citar dois dos mais influentes. $^{7}$ Eles percebiam uma debilidade e uma

${ }^{5}$ Secretaria do Patrimônio Histórico e Artístico Nacional.

${ }^{6}$ O livro Leituras brasileiras (Veloso; Madeira, 1999) é um bom guia para a compreensão desse contexto cultural e histórico. Nos anos 20, ressaltam o papel do Modernismo como virada intelectual e política e, nos anos 40, o desdobramento da obra de Sérgio Buarque, sem falar na influência de Freyre e Buarque nos anos 30.

${ }^{7}$ É interessante que o citado livro de Veloso e Madeira (1999) também recorre a uma categoria foucaultiana, a da ideia de episteme para tematizar a influência política e cultural desses autores na época. Essa categoria ajuda a pensar como o conhecimento institucionalizado pode contribuir na mudança dos rumos de um processo de construção nacional. incapacidade histórica do povo brasileiro para guiar seus próprios assuntos e, assim, apostavam na força do Estado e na organização de suas instituições para a consolidação da construção nacional. Enquanto eles apostavam no Estado como ponto de partida para a construção nacional na dimensão necessária daquele momento, Freyre e Holanda apostavam na sociedade como ponto de partida. Se pensarmos bem, há uma concordância entre tais perspectivas, aparentemente opostas. A suavidade do povo se completa perfeitamente com o fortalecimento do Estado para a política corporativa e integradora de Vargas. Aqui, o saber-poder da brasilidade surge em versões distintas, porém complementares, e contribui incisivamente, mediante a história e a literatura, para a construção nacional efetiva naquele momento.

Outra dimensão importante do processo de construção nacional precisa lembrar como os mitos, ou seja, as compreensões que uma sociedade tem sobre si mesma, constituem parte fundamental da ação coletiva. Por que sobrevivem certas ideias sobre a brasilidade, que foram pensadas a partir de uma realidade em mudança desde o século XIX, ou seja, como o saber-poder da brasilidade se atualiza, pode ser entendido com o auxílio de uma literatura que investigou a natureza histórica da nação moderna. Benedict Anderson, em seu clássico trabalho sobre as "comunidades imaginadas" (1991), investigou como o fato de se ter uma identidade nacional se tornou um requisito indispensável para qualquer sociedade moderna organizada em torno de um Estado nacional. Isso porque a nova forma de organização política e econômica que se esboçava necessitava de uma justificativa moral e simbólica, ou seja, de um conteúdo cognitivo compartilhado socialmente por todas as classes, que as fizesse se sentirem um todo coletivo, pertencentes a uma só identidade.

Se pensarmos a construção nacional brasileira dentro desse esquema teórico, buscando situá-lo na realidade histórica da América do Sul naquele contexto do século XIX, poderemos 
tematizar porque as ideias centrais sobre a brasilidade, sobre a negação e aversão que ela tem a qualquer conflito, parecem permanecer explicando o Brasil e influenciando a vida prática de todas as suas classes. A investigação de Reinhard Bendix, em seu livro Construção nacional e cidadania (1996) auxilia no entendimento, inspirado em Weber, de que cada caso de construção nacional reúne, de forma contingente, os elementos materiais e imateriais modernos necessários para sua realização. O ponto mais interessante em sua análise é acerca da falsa dicotomia entre tradição e modernidade. Todo caso de construção nacional precisa, para sua legitimação, inventar uma falsa ruptura com um passado que, ao mesmo tempo, permanece no imaginário como motivo de orgulho e coesão social. Essa compreensão da combinação contingente entre elementos materiais e imateriais na construção nacional parece apresentar uma profunda afinidade com a ideia de saber-poder de Foucault. Ou seja, não compreendemos nosso processo histórico de construção nacional sem perceber como a brasilidade, como saber-poder, é, ao mesmo tempo, um conjunto de ideias e um conjunto de práticas que se atualiza com o tempo, em instituições concretas.

No caso brasileiro, a interpretação que permaneceu dominante sobre nossa singularidade sugere uma relação especial entre tradição e modernidade. Por isso, a ideia da falsa dicotomia em Bendix é importante. A ideia predominante no mito da brasilidade é que a modernidade nunca superou completamente a tradição. Na verdade, a tese predominante é que elas convivem articuladas, de modo que a primeira sutilmente ressignifique a última. Tal tese surge de diversas maneiras ao longo do século XX. Uma delas, por exemplo, é o livro Os dois brasis de Jacques Lambert (1976), que a situa na dimensão do contraste entre as realidades rurais e urbanas no Brasil. A mais influente, entretanto, é a conhecida obra de Roberto DaMatta, principalmente em seu livro Carnavais, malandros e heróis (1978). Ele constrói a versão teórica mais atualizada sobre a brasilidade. Sua tese sobre a capacidade brasileira de driblar suavemente os problemas, amenizando todos os conflitos, reproduz, ao invés de criticar, e legitima como ciência tudo aquilo que o brasileiro pensa sobre si mesmo (Souza, 2000).

Tal perspectiva não leva em conta que a própria modernidade, em suas formas objetivas de reprodução, também vira "tradição", ou seja, desenvolve padrões institucionais e morais próprios que passam a funcionar como se fossem naturais. Isso é o que parece sugerir o citado livro de Bendix e, no caso brasileiro, o trabalho de Renato Ortiz, A moderna tradição brasileira (1988), que toma como mote da análise o advento da indústria cultural no Brasil. Essa concepção de Bendix apresenta interessante afinidade com a ideia de saber-poder, pois ela também procura explicitar como saberes novos se estabelecem, viram "tradição", quando substituem saberes outrora estabelecidos. Ambas as perspectivas sugerem que qualquer condição dominante, seja de grupos ou classes de naturezas distintas, está sempre em aberto, uma vez que se sustenta apenas por lutas materiais e simbólicas constantes. O saber-poder do mito da brasilidade só se tornou "tradição" porque sobreviveu diante de ideias menos eficazes.

A recorrência à literatura dominante no Brasil é importante para analisar como a categoria do conflito social é suavemente apagada de nosso mito nacional e como esse fato pode apresentar consequências negativas para nossa vida política coletiva, ou seja, para nosso aprendizado político, nosso engajamento coletivo e nossa prescrição de metas políticas coletivas. Vimos que, em nosso imaginário, na opinião que temos sobre nós mesmos, em parte reproduzida pela academia, não somos um povo marcado pelo conflito. Agora, pode ser útil tentar compreender porque nosso mito precisou desse conteúdo específico e de nenhum outro. Isso depende de uma reflexão sobre o momento histórico, o espaço e o tempo no Ocidente, no qual se forma o Estado e se inicia o processo de uma moderna sociedade brasileira, ou seja, o início de nossa 
construção nacional. O citado livro de Bendix sugere que se tematize exatamente essa contingência histórica específica.

Como vimos, a realidade histórica da Europa durante a construção nacional de Inglaterra e França, ainda que cada um desses casos tenha vivenciado experiências coletivas bastante distintas entre si, foi marcada por guerras e conflitos internos e externos que obrigaram tais povos a uma autopercepção como guerreiros e herdeiros de legados sociais fortes e dinâmicos. $\mathrm{O}$ momento histórico de constituição do Estado nacional brasileiro é totalmente diferente. Não é novidade que se tratou de uma independência política e de uma rearticulação de uma dependência econômica, como mostra Florestan no citado livro, A revolução burguesa no Brasil. Esse é um contexto totalmente diferente das formações nacionais europeias, e que ajuda a explicar por que não tivemos mitos realmente concorrentes com o da brasilidade pacífica. Diferentemente dos casos europeus, parece que aqui predominaram apenas versões diferentes de um mesmo saber-poder do mito nacional, ligadas a frações antagônicas de uma mesma classe dominante de ascendência portuguesa, e não a disputa entre saberes-poderes com mitos distintos exatamente por representarem classes dominantes de perfil e histórico totalmente distintos, como nas disputas entre aristocratas e burgueses em alguns casos europeus.

Em primeiro lugar, o Brasil não era uma nação que surgia no novo continente competindo por alguma hegemonia ou liderança com outras nações, o que exigiria um mito, um saberpoder, de conteúdo guerreiro para sua legitimidade. É uma nação que se torna independente, pondo fim a um pacto colonial, mas que já se inicia desenvolvendo um capitalismo dependente, uma economia interna politicamente independente, mas economicamente dependente no contexto internacional, como mostra Florestan, situando-a no momento e no espaço do capitalismo mundial nos quais nasce. Trata-se de uma espécie de Estado nacional “passivo", e, por isso, parece razoável pensar que não faria sentido, em nosso caso, um mito nacional "ativo", como nos citados casos europeus que necessitaram disso por motivos bem distintos.

Logo, começa a fazer sentido o conteúdo do mito que encontramos já presente, ainda que não sistematizado, nos discursos de D. Pedro I e do Patriarca da Independência, José Bonifácio, que escrevia também os discursos do Imperador. Tratava-se de legitimar a representação, proteção e liderança por parte do primeiro, sobre um povo bom, inocente, pacífico e hospitaleiro (Maciel, 2007). Em segundo lugar, além de corresponder às necessidades e condições objetivas do contexto que precisava legitimar, nosso mito, como qualquer mito moderno nacional, desenvolve-se relacionalmente, em oposição a outros. Nesse ponto, o caso parece bem diferente dos europeus que construíram seus mitos tentando provar que, de alguma maneira, eram melhores, mais fortes, mais legítimos e mais autênticos que seus vizinhos. Em nosso caso, isso não parecia fazer muito sentido, pois a relação direta era muito mais entre colônias que se tornavam independentes e suas antigas metrópoles do que entre as novas nações. A realidade objetiva e histórica nos conectava muito mais com o velho mundo do que com as Américas. De modo que nosso mito precisava provar que, em alguma dimensão, éramos autênticos e diferentes dos Europeus, e não dos norte-americanos, cuja comparação acabou se tornando muito mais comum entre nós. Esse contraste já se esboça no próprio Bonifácio, que tratava estrategicamente os europeus como invasores e os brasileiros como ingênuos explorados.

É razoável considerar que nenhum mito surge por acaso, nem se resume à mera invenção de algumas elites interessadas no poder. Ele é fruto de uma construção intelectual e moral que reflete, em alguma medida, a realidade mais imediata vivida pela coletividade em questão. Esse é o sentido do saber-poder em Foucault. Em nosso caso, o grande dado empírico era o convívio entre as três raças. Como uma espécie 
de edição da história, o mito não reproduz toda a realidade, mas seleciona parte dela facilmente visível no cotidiano da nação e compreensível ao senso comum e a exagera. $\mathrm{O}$ mito tem uma relação distanciada com o todo e exagerada com a parte. Basta refletir um pouco sobre o que era o convívio das três raças para vermos por que não é por acaso a centralidade da ideia de democracia racial no saber-poder do mito da brasilidade.

Não é novidade que a escravidão, no Brasil, foi um mundo de terror. Basta olhar um pouco da obra de Joaquim Nabuco, principal referência, para encontrar dados empíricos sobre o fato (Nabuco, 1999). Ademais, são conhecidas as histórias de revoltas e conflitos locais no Brasil, desde o século XIX, como a Cabanagem, Palmares, Canudos e, mais recentemente, o anarcosindicalismo do século XX. Logo, o convívio entre as raças, e também entre as classes, no Brasil, não é tão pacífico como sugere o mito. No entanto, a narrativa que temos sobre nós mesmos não é a de um povo politizado e contestador, mas sim a do povo alegre e pacífico. Nesse contexto, não podemos desconsiderar a força que o saber-poder da ideia de uma democracia racial operou entre nós, ainda que, nas últimas décadas, vasta literatura e o movimento negro tenham criticado incisivamente tal ideia. O mito da democracia racial ainda funciona como velador e suavizador de conflitos de classe, gênero e identitários como um todo, no processo constante de atualização de nossa construção nacional. Dentre inúmeros exemplos, temos o discurso de posse de Fernando Henrique, quando assume a presidência, que se refere aos brasileiros como o povo por excelência da democracia racial, e também inúmeras falas do Presidente Lula no mesmo tom, o que se resume no slogan de seu governo: "Brasil, um país para todos". Assim como as falas de Bonifácio e D. Pedro I, tais falas oficiais atuais não são por acaso. Mobilizam e atualizam boa parte da crença do brasileiro sobre si mesmo.

É interessante notar que o mito possui certa ambiguidade em seu conteúdo, pois, afinal, se trata de senso comum e ele é sempre parcial e fragmentado, o que faz com que conteúdos internos, incompatíveis aos olhos da ciência, convivam no imaginário popular sem se contradizer (Evans-Pritchard, 1978). Em nosso caso, a mesma ideia de povo pacífico nos remete a de povo passivo, despolitizado, desinteressado, malandro, incompetente. Assim, temos também um lado negativo em nosso mito. Entretanto, pesquisas recentes mostram que o que predomina no imaginário brasileiro é o lado positivo do mito. ${ }^{8}$

Isso nos impele a tentativa de evitar certa caricatura da cultura brasileira. Os dados sobre a presença de conflitos históricos e de resistência popular em nossa construção nacional, por um lado, e a presença de traços negativos sobre nossa identidade em nosso imaginário, por outro, ajudam a comprovar que a parte da positividade, editada e essencializada pelo mito, é apenas uma meia-verdade de nossa cultura, se considerarmos esse termo como o resultado do encontro histórico entre forças objetivas, como a economia e a política, e as ideias que lhes correspondem e as legitimam.

Uma parte importante da edição de nosso mito em favor dos traços positivos parece ser certa valorização ideológica da sociedade, considerando-a quase como sinônimo de cultura, em contraposição ao Estado, como vimos na diferença parcial entre os "culturalistas" Freyre e Sérgio Buarque e os "Estadistas" Oliveira Vianna e Alberto Torres. ${ }^{9}$ A obra madura de Freyre, como a coletânea Palavras repatriadas (2003), transforma em teoria uma parte do que o brasileiro pensa sobre si mesmo quanto a esse ponto. A ideia predominante do artigo "O caráter nacional brasileiro", nesse livro, é a de que, no Brasil, a democracia está no próprio povo e, por isso, não é um grande problema que ela falte no Estado. O contexto da afirmação era o da dita-

\footnotetext{
Refiro-me a duas pesquisas realizadas em 1995, uma pela Vox Populi e outra pela FGV (Chaui, 2000), e a outra mais recente, de 2005, intitulada "A construção social da subcidadania” (Souza, 2006).

${ }^{9}$ Para uma boa apresentação de suas obras, ver, respectiva-
} mente, Brandão (2000) e Kuntz (2000). 
dura militar. Assim, Freyre atualiza o mito, transformando a própria sociedade numa espécie de Leviatã, onde reinam todas as virtudes. Ao contrário dos casos Europeus, nos quais "a política é a continuação da guerra por outros meios", como afirma Foucault no citado livro, no Brasil, a política seria a mera continuação da política, no restrito sentido de um espaço de acordos sem conflito. Essa perspectiva opera duas edições do mito sobre nossa realidade. Primeiro, separa normativamente sociedade de Estado, o que é inimaginável em qualquer caso concreto de Estados nacionais modernos, nos quais Estado e sociedade são partes articuladas de uma mesma condição moderna (Souza, 2006). As ideias de saber-poder de Foucault e de construção nacional de Bendix também sugerem tal síntese. Segundo, reproduz, na dimensão do Estado, mesmo considerado algo à parte da sociedade, os mesmos critérios definidores da brasilidade, ou seja, aqueles que afirmam sua positividade negando o conflito.

Por fim, outro ponto importante na comparação esboçada neste artigo é que, no caso brasileiro, parece que o mito da pacificidade não teve nenhum grande rival interno, como sugere Foucault ter ocorrido no caso da Inglaterra, e nem externo, como na França. Novamente, o contexto internacional do surgimento do Estado brasileiro pode sugerir apontamentos interessantes nesse sentido. Se considerarmos a conhecida história brasileira dessa época, podemos compreender que, internamente - e, nisso, muito diferente dos europeus -, o Brasil não tinha muitos grupos poderosos política e economicamente que deveriam se enfrentar na lógica do saber-poder pela hegemonia do Estado. Sabemos que a geração de D. Pedro e Bonifácio era de uma classe dominante branca, fundamentada no poder econômico da escravidão, ou seja, consideravelmente homogênea. Naturalmente, qualquer grupo dominante terá sempre conflitos internos. Mas isso parece muito diferente de casos históricos em que grupos totalmente distintos em sua formação e autopercepção, como a aristocracia e a burguesia, se enfrentam pela hegemonia nacional. Externa- mente, nosso mito não precisava provar nenhuma superioridade nem hegemonia na América, pois, naquele momento, esse tipo de rivalidade faria pouco sentido histórico. Apenas precisava legitimar sua evidente singularidade de uma formação trirracial.

Agora, precisamos retomar a ideia de que os mitos influenciam na vida prática de uma sociedade, pensando aqui o caso específico da vida prática coletiva do brasileiro, de modo a compreender a afinidade eletiva entre o conteúdo predominante de nosso mito e nossa vida política, com ênfase no objetivo central de contribuir para uma reflexão sobre nosso potencial de aprendizado político e seus efeitos para nossa vida coletiva. É o que buscaremos desenvolver na parte conclusiva deste artigo.

\section{CONCLUSÃO - O saber-poder do mito da brasilidade $\mathrm{e} o$ aprendizado político no Brasil}

Já sugerimos o processo de construção nacional como síntese de dimensões práticas e ideais de uma sociedade tipicamente moderna. A tentativa de contribuir para uma teoria do aprendizado político pode ser uma forma produtiva de compreender tanto por que certas ideias predominam no imaginário como por que contribuem para determinados efeitos práticos. Na primeira dimensão, vimos que as ideias negadoras do conflito na brasilidade tiveram uma razão de ser, dentro de condições concretas de saber-poder, desde nossa independência política. Na segunda dimensão, podemos analisar agora por que esse conteúdo específico de nosso mito parece contribuir para um potencial fraco de aprendizado político entre os brasileiros. O ponto em questão é ressaltar como e por que um processo de construção nacional específico pode ou não apresentar um potencial fraco ou forte de aprendizado político.

Cabe notar que não nos interessa filiação a algum pós-estruturalismo que rodeie a ideia de saber-poder e nem ao contexto do 
pragmatismo que contribui para o florescimento da ideia de aprendizado político. A articulação de tais ideias pretende apenas aproveitar o que puder haver de produtivo em uma síntese entre elas que contribua para a compreensão do processo histórico de construção nacional no caso brasileiro. Todo aprendizado político é fruto de algum saber-poder dominante e pode, em contrapartida, se transformar em força social em favor de saberes-poderes dominados. O processo de construção nacional, em cada caso específico, apresenta sempre um histórico dessa dinâmica de luta entre saberes e aprendizados.

Como ressaltamos no início, a ideia de construção nacional remete-nos à articulação entre as dimensões materiais e imateriais de realização de uma sociedade moderna sob os moldes do Estado nacional moderno. A primeira dimensão é visível em instituições concretas como o Estado, o mercado e a esfera pública. A segunda dimensão é compreensível por meio das ideias de saber-poder e de mito nacional, sendo esse último uma espécie de saber-poder tipicamente moderno. A articulação teórica entre ambas as dimensões permite auxiliar na compreensão do processo histórico de construção nacional. Mediante o conteúdo específico da brasilidade como mito nacional, como saber-poder dominante em nosso processo de construção nacional, sugerimos a hipótese de um fraco aprendizado político, considerando que o conteúdo de ideias negadoras do conflito - pacificidade, bondade e generosidade - tenha pouca afinidade com o comportamento político de engajamento em assuntos coletivos.

Para ficar mais claro: a ideia de aprendizado político, como vimos, precisa compreender as dimensões reflexivas e não-reflexivas do aprendizado. A dimensão reflexiva é mais facilmente visível, como, por exemplo, em nosso aprendizado escolar. É nele que, dentre outras coisas, reflexivamente, aprendemos o mito da democracia racial e da bondade do brasileiro. A dimensão não-reflexiva, menos visível, trata da capacidade de o indivíduo, em sua socialização, aprender na prática o que é a brasilidade. Somos socializados a partir das ideias de não-conflito e de democracia racial, bem como por meio de todos os outros traços da brasilidade, ou seja, as ideias de pacificidade, bondade, sensualidade e hospitalidade, ressaltadas por vasta literatura. Como vimos, tais ideias se tornam prática mediante instituições concretas da vida pública.

Um ponto que pode ser útil na tarefa de articular construção nacional e aprendizado político é a tese da democracia como cooperação reflexiva, que Axel Honneth toma de John Dewey (Honneth, 2000). Um pressuposto básico é o de que todas as sociedades nacionais modernas atualmente perseguem o ideal democrático. $\mathrm{O}$ alcance de tal ideal, entretanto, depende de indivíduos que se considerem capazes, merecedores e responsáveis por tal objetivo, e que também considerem os outros de sua coletividade como iguais e, por isso, mesmo como parceiros em tal empreitada coletiva (2000). Se tal hipótese fizer algum sentido, podemos pensar que o potencial despolitizante do saber-poder da brasilidade, calcado em seu mito de negação do conflito, é um forte impedimento para tal tipo de comportamento político articulado. É claro que isso não pode naturalizar uma condição brasileira como incapaz de aprendizado político, mas simplesmente tentar auxiliar na compreensão de suas dificuldades.

Se os mitos nacionais exercem papel significativo na vida política da nação, então seria razoável tentar conectar sua função nesse processo de cooperação reflexiva, fundamental para o desenvolvimento da construção nacional desde seu desdobramento inicial em diante. Nesse ponto, a questão que parece importante é pensar em que medida um mito que nega o conflito - e que, por isso, faz os brasileiros se perceberem como pacíficos e despolitizados - pode interferir em uma cooperação reflexiva. Se essa cooperação depende de uma capacidade de ação em coletividade, ou seja, de um aprendizado político que, por sua vez, depende de uma vida de enfrentamento político em busca de metas 
coletivas comuns, então o mito da pacificidade parece não colaborar nessa direção.

Se o mito da brasilidade significa um saber-poder que sugere uma conduta de nãoenfrentamento, parece razoável pensar em sua afinidade eletiva com certa dificuldade de o brasileiro se engajar em assuntos coletivos. É certo que outras razões sociológicas que não caberia explorar aqui podem contribuir para essa constatação genérica. Também é certo que o Brasil já presenciou e ainda presencia movimentos sociais altamente politizados, como o é atualmente e já há bastante tempo o MST. Mas sabemos também que se trata de histórias muito específicas em contextos nos quais as lutas foram inevitáveis, inclusive por fortes razões materiais.

Entretanto, ciente de que um amplo tema como este está longe de ser esgotado e exigiria mais pesquisas empíricas para um desdobramento satisfatório, este artigo buscou contribuir para uma análise que considere o papel do conteúdo da brasilidade pacífica em nosso processo de construção nacional e em nosso concomitante aprendizado político. Como vimos nos casos da Inglaterra e da França, um conteúdo mitológico mais contestador e guerreiro parece ter contribuído para um aprendizado democrático mais dinâmico. No caso brasileiro, uma aparente dificuldade em lidar com assuntos coletivos e de se perceber como membro responsável, útil e capaz de uma comunidade política pode encontrar, no mito da pacificidade, uma boa possibilidade de estudos, ainda hoje, para sua compreensão.

No geral, o que está em jogo é compreender como construção nacional e aprendizado político são conceitos que remetem a realidades empíricas indissociáveis. A sugestão aqui é que não existe o primeiro sem o segundo. A hipótese levantada, e que exigiria estudos históricos e sociológicos mais profundos, não é a de que inexista aprendizado político no Brasil, pois, sem ele, inexiste construção nacional como um processo social e histórico dinâmico, em constante mudança. Se buscarmos articular o saber-poder da brasilidade, mediante seu mito específico negador de conflitos, sedimentado em ideias como pacificidade e democracia racial, com nosso potencial específico de aprendizado político, poderemos ver que existe um aprendizado político, porém com fraco potencial de articulação democrática e engajamento em assuntos e metas coletivas. A articulação dessa dificuldade, que não é natural ou cultural, mas sociológica e histórica, permite compreendê-la como uma possibilidade de mudança e de avanço no comportamento político do brasileiro de todas as classes. Como aprendemos com todos os clássicos da sociologia, o diagnóstico de um problema é sempre o primeiro passo para o enfrentamento de sua solução prática. O histórico do saber-poder da brasilidade possui um longo caminho, confunde-se com nossa própria história como nação moderna, e sua compreensão em si já é uma pequena parte do aprendizado político que precisamos adquirir, de modo a caminhar rumo a um processo de construção nacional ainda mais politizado e democrático.

(Recebido para publicação em outubro de 2009) (Aceito em fevereiro de 2010)

\section{REFERÊNCIAS}

ANDERSON, Benedict. Imagined communities. London; New York: Verso, 1991.

ARAÚJO, Ricardo Benzaquen de. Guerra e Paz. Rio de Janeiro: Editora 34, 1994.

BENDIX, Reinhard. Nation-Building \& citizenship. Studies of our changing social order. New York: Transaction Pub, 1996. BRANDÃO, Gildo M. “Oliveira Viana. Populações meridionais do Brasil”. In: MOTA, Lourenço D. Introdução ao Brasil 2. Um banquete no trópico. São Paulo: Senac, 2000.

CHAUI, Marilena. Brasil, mito fundador e sociedade autoritária. São Paulo: Perseu Abramo, 2000.

DAMATTA, Roberto. Carnavais, malandros e heróis. Rio de Janeiro: Zahar, 1978.

DUMONT, Louis. German Ideology. From France to Germany and Back. Chicago and London: University of Chicago Press, 1994

EVANS-PRITCHARD, E. E. Bruxaria, oráculos e magia entre os Azande. Rio de Janeiro: Zahar, 1978.

FERNANDES, Florestan. A revolução burguesa no Brasil. São Paulo: Globo, 2006.

FOUCAULT, Michel. Em defesa da sociedade. São Paulo: Martins Fontes, 2005. 
FREYRE, Gilberto. Casa Grande \& Senzala. São Paulo: Global, 2004.

Palavras repatriadas. Brasília; São Paulo: UnB Imprensa Oficial de SP, 2003. 1990. Sobrados e mucambos. Rio de Janeiro: Record,

HOBSBAWN, Eric J. Nações e nacionalismo desde 1780. Rio de Janeiro: Paz e Terra, 1990

HOLANDA, Sérgio B. Raízes do Brasil. São Paulo: Companhia das Letras, 1999.

HONNETH, Axel. Democracia como cooperacão reflexiva: John Dewey e a teoria democrática hoje. In: SOUZA, Jessé (Org.) Democracia hoje. Brasília: UnB, 2001.

KUNST, Rolf. Alberto Torres. A organização nacional. In: MOTA, Lourenço D. Introdução ao Brasil 2. Um banquet no trópico. São Paulo: Senac, 2000.

LAMBERT, Jacques. Os dois brasis. São Paulo: Brasiliana, 1976.

LEITE, Dante Moreira. O caráter nacional brasileiro. São Paulo: Pioneira, 1969.

MACIEL, Fabrício. O Brasil-nação como ideologia. São Paulo: Annablume, 2007.
MOTA, Carlos Guilherme. Ideologia da cultura brasileira. São Paulo: Ática, 1985.

NABUCO, Joaquim. O abolicionismo. Rio de Janeiro: Nova Fronteira, 1999.

ORTIZ, Renato. A moderna tradição brasileira. São Paulo: Brasiliense, 1988.

OSTERGARD, Uffe. The danish path to modernity. Thesis Eleven, [S.l.], v.77, p.25-43, mayo, 2004.

RUBINO, Silvana. O mapa do Brasil passado. Revista do Patrimônio Histórico e Artístico Nacional, Rio de Janeiro, n.24, 1996.

SOUZA, Jessé. A construção social da subcidadania. Belo Horizonte; Rio de Janeiro: Iuperj, 2003.

. A invisibilidade da desigualdade brasileira. Belo Horizonte: Edufmg, 2006

A modernização seletiva. Brasília: UnB, 2000.

TAYLOR, Charles. As fontes do self. São Paulo: Edições Loyola, 1997.

VELOSO, Marisa; MADEIRA, Angélica. Leituras brasileiras. Itinerários no pensamento social e na literatura. São Paulo: Paz e Terra, 1999.

WITTROCK, Björn mayo,. The making of Sweden. In.: Thesis Eleven, [S.l.], v.77, p.45-63, mayo. 2004. 


\section{NATION BUILDING AND POLITICAL LEARNING: KNOWLEDGE-POWER OF BRAZILDOM}

\section{Fabrício Maciel}

This paper seeks to unite comparative theoretical elements among Brazilian and European processes of national construction, in order to analyze the specificity of the former's national myth and its relationship to political learning in Brazil. In order to do this, parts 1 and 2 of this paper seek, in view Michel Foucault's "In defense of society" (2005), to examin the mythological narratives of nationbuilding processes in England and France respectively. The third part seeks to analyze, mainly in view of the work of Gilberto Freyre, the specificity of the process of nation building and the myth of denial of conflict in Brazil. The final section seeks to analyze a possible elective affinity between the national myth and a disability in political learning in Brazil.

KEYwORDS: nation building, national myth, conflict, political learning, knowledge-power.

\section{CONSTRUTION NATIONALE ET APPRENTISSAGE POLITIQUE: LE SAVOIR- POUVOIR DE LA BRASILITE}

\section{Fabrício Maciel}

Cet article se veut de rassembler les éléments théoriques comparatifs des processus européens et du processus brésilien de construction nationale afin d'analyser la spécificité du mythe national de ce dernier et sa relation avec l'apprentissage politique au Brésil. C'est ainsi que la première et la deuxième partie de l'article cherchent, à partir de l'œuvre de Michel Foucault "Il faut défendre la société" (2005), à analyser les récits mythologiques des processus de construction nationale respectivement en Angleterre et en France. La troisième partie examine, surtout à partir de l'œuvre de Gilberto Freyre, la spécificité du processus de construction nationale et le mythe de la négation de conflit au Brésil. La dernière partie se propose d'analyser une affinité élective possible entre le mythe national et une difficulté d'apprentissage politique au Brésil.

MotS-CLÉs: Construction nationale, mythe national, conflit, apprentissage politique, savoirpouvoir.

Fabrício Maciel - Doutorando em Ciências Sociais pela Universidade Federal de Juiz de Fora. Pesquisador do Centro de pesquisa sobre desigualdade, coordenado pelo Prof. Jessé Souza na UFJF. Autor da dissertação de mestrado Trabalho e reconhecimento na modernidade periférica, defendida em 2007 na UENF. Realiza doutorado sanduíche em Freiburg-Alemanha. Autor do livro O Brasil-nação como ideologia: a construção retórica e sócio-política da identidade nacional (São Paulo: Annablume, 2007). Dentre as publicações mais recentes destacam-se artigos em livro editado por Jessé Souza Os batalhadores brasileiros. ....(Belo Horizonte: Editora UFMG, 2010) e artigo em co-autoria (Grillo, A. ) no livro A ralé brasileira. Quem é como vive. Editado por Jessé Souza (Belo Horizonte: Editora UFMG, 2010). 